and when NPPV should be applied in patients with stable hypercapnic COPD. Recent research indicates that the technique of how NPPV is applied is the crucial issue regarding the acceptance and effectiveness of NPPV. Here, the new concept of high-intensity NPPV has provided promising results with respect to gas exchange, lung function, treatment compliance, dyspnoea and HRQL. In addition, NPPV applied during physical activity and rehabilitation has emerged as a new potential indication for NPPV aiming to improve gas exchange, functional status and exercise-induced dyspnoea. Although the importance of proven NPPV-associated improvements in gas exchange, symptoms, functional status and HRQL is undisputed, we need an answer as soon as possible to the question: 'Are these new approaches also capable of improving long-term survival?'

Competing interest BS is sponsored by Resmed and Heinen \& Löwenstein to give talks on mechanical ventilation.

Provenance and peer review Commissioned; not externally peer reviewed.

Thorax 2010:65:765-767.

doi:10.1136/thx.2010.145276

\section{REFERENCES}

1. Elliott MW, Simonds AK, Carroll MP, et al. Domiciliary nocturnal nasal intermittent positive pressure ventilation in hypercapnic respiratory failure due to chronic obstructive lung disease: effects on sleep and quality of life. Thorax 1992:47:342-8.

2. Wijkstra PJ, Lacasse $Y$, Guyatt GH, et al. A metaanalysis of nocturnal noninvasive positive pressure ventilation in patients with stable COPD. Chest 2003;124:337-43.

3. Simonds AK, Elliott MW. Outcome of domiciliary nasal intermittent positive pressure ventilation in restrictive and obstructive disorders. Thorax 1995; 50:604-9.

4. Casanova C, Celli BR, Tost $L$, et al. Long-term controlled trial of nocturnal nasal positive pressure ventilation in patients with severe COPD. Chest 2000;118:1582-90.

5. Clini E, Sturani C, Rossi A, et al. The Italian multicentre study on noninvasive ventilation in chronic obstructive pulmonary disease patients. Eur Respir J 2002;20:529-38.

6. McEvoy RD, Pierce RJ, Hillman D, et al. Nocturnal non-invasive nasal ventilation in stable hypercapnic COPD: a randomised controlled trial. Thorax 2009;64:561-6.

7. Ware JE Jr, Sherbourne CD. The MOS 36-item Short-Form Health Survey (SF-36). I. Conceptual framework and item selection. Med Care 1992:30:473-83.

8. Jones PW, Quirk FH, Baveystock CM. The St George's Respiratory Questionnaire. Respir Med 1991;85(Suppl B):25-31.

9. Testa MA, Simonson DC. Assesment of quality-oflife outcomes. N Engl J Med 1996;334:835-40.

10. Windisch W, Freidel K, Schucher B, et al. The Severe Respiratory Insufficiency (SRI) Questionnaire: a specific measure of health-related quality of life in patients receiving home mechanical ventilation. J Clin Epidemiol 2003;56:752-9.

11. Windisch W, Budweiser S, Heinemann F, et al. The Severe Respiratory Insufficiency Questionnaire was valid for COPD patients with severe chronic respiratory failure. J Clin Epidemiol 2008;61:848-53.
12. Windisch W. Impact of home mechanical ventilation on health-related quality of life. Eur Respir $J$ 2008; $32: 1328-36$

13. Carone M, Bertolotti G, Anchisi F, et al. Analysis of factors that characterize health impairment in patients with chronic respiratory failure. Quality of Life in Chronic Respiratory Failure Group. Eur Respir J 1999;13:1293-300.

14. Windisch W, Dreher M, Storre JH, et al. Nocturnal non-invasive positive pressure ventilation: physiological effects on spontaneous breathing. Respir Physiol Neurobiol 2006;150:251-60.

15. Windisch W, Haenel M, Storre JH, et al. Highintensity non-invasive positive pressure ventilation for stable hypercapnic COPD. Int J Med Sci 2009;6:72-6.

16. Windisch W, Kostic S, Dreher M, et al. Outcome of patients with stable COPD receiving controlled noninvasive positive pressure ventilation aimed at a maximal reduction of $\mathrm{PaCO}_{2}$. Chest 2005;128:657-62.

17. Windisch W, Vogel M, Sorichter $S$, et al. Normocapnia during nIPPV in chronic hypercapnic COPD reduces subsequent spontaneous $\mathrm{PaCO}_{2}$. Respir Med 2002;96:572-9.

18. Windisch W, Storre JH, Sorichter S, et al Comparison of volume- and pressure-limited NPPV at night: a prospective randomized cross-over trial. Respir Med 2005:99:52-9.

19. Dreher M, Storre JH, Schmoor C, et al. Highintensity versus low-intensity non-invasive ventilation in patients with stable hypercapnic COPD: a randomised crossover trial. Thorax 2010:65:303-8.

20. Dreher M, Storre JH, Windisch W. Noninvasive ventilation during walking in patients with severe COPD: a randomised crossover trial. Eur Respir J 2007:29:930-6

21. Duiverman ML, Wempe JB, Bladder G, et al. Nocturnal non-invasive ventilation in addition to rehabilitation in hypercapnic patients with COPD. Thorax 2008;63:1052-7.

\title{
Lung Alerts: promoting education and encouraging new authors
}

\author{
Angshu Bhowmik, ${ }^{1}$ Jenni Quint ${ }^{2}$
}

Lung Alerts were introduced by Wisia Wedzicha, Editor-in-Chief in 2003 to increase the educational content of the journal. The aim was to commission brief summaries of papers on respiratory topics published in non-respiratory journals, thereby attracting a broader interest particularly among doctors in training. It

\footnotetext{
${ }^{1}$ Homerton Hospital, London, UK; ${ }^{2}$ Department of Academic Respiratory Medicine, Royal Free and University College Medical School, Royal Free Hospital, London, UK
}

Correspondence to Angshu Bhowmik, Homerton Hospital, Homerton Row, London E9 6SR, UK; a.bhowmik@qmul.ac.uk was also intended to allow readers to keep abreast of publications in journals to which Respiratory Specialists are less likely to subscribe.

At the time of writing, 372 Lung Alerts have so far been published from 2003 until June 2010 at an average of 4.25 per month. A further 15 are in press.

Of the 387 Lung Alerts we have edited, looking at contributors from a regional perspective, the largest proportion (44\%) were from London and the Kent, Surrey and Sussex Deaneries. 8\% of contributors have been from outside the UK. The North Western (6\%), South West Peninsula $(5 \%)$, Eastern $(5 \%)$ and LNR (Leices- tershire, Northamptonshire and Rutland) (4\%) Deaneries have been the other major sources of authors of Lung Alerts.

Fifty per cent have been written by Specialist Registrars or equivalent, 20\% by doctors in various grades which previously fell under the category of 'Senior House Officer', 10\% by 'Research Fellows', $7.5 \%$ by Consultant or equivalent doctors, $1.6 \%$ by Foundation 1 doctors and three of the Alerts have been written by students. The remainder were written by doctors of various other grades including Speciality doctors and Associate Specialists. We are hopeful that the experience of being able to publish in Thorax will have led to many of those who were not already committed to careers in Respiratory Medicine and Science being drawn to this speciality!

Over the years, 70 journals have provided the sources for the papers summarised in Lung Alerts. The largest number has been from the New England Journal of Medicine (99) with other major contributors being the Lancet (48) and 
$J A M A$ (24). The BMJ, with 19 papers, has also provided us with much material of interest.

One hundred and sixty-four of the Lung Alerts were about treatments and management strategies of various lung diseases. Ninety-four concerned pathological mechanisms of disease, with an increasing number in the last 2 years about genetic factors relating to lung disease, reflecting the increasing interest and knowledge about genetics in the published literature. We are confident that this trend will continue and we will gain a greater understanding of the genetics of pulmonary disease in the coming years.

The diseases of greatest interest in the general medical journals seem to be asthma and allergy, with $19 \%$ of the Lung Alerts. This was followed closely by lung cancer $(16 \%)$, infection (excluding tuberculosis (TB)) (15\%) and chronic obstructive pulmonary disease (COPD) (12\%). TB garnered $7 \%$ of the alerts, with cystic fibrosis following at $4 \%$.

Some of the Lung Alerts which we published are memorable to us for particular points of interest. For example, we learned that allergic sensitisation to peanuts may occur through inflamed skin rather than only the oral route. ${ }^{1}$ Other Alerts have reported early studies which have led to greater understanding of new procedures or treatments-for example, radio-frequency ablation ${ }^{2}{ }^{3}$ and gefitinib ${ }^{4}$ in the treatment of lung cancer. We alerted our readers to a useful new method of assessing patients with COPD: the BODE index described in the New England Journal of Medicine in 2004. ${ }^{5}$ We have reported studies that reinforce good practice-for example, PET-CT to reduce futile thoracotomies $^{6}$ and the use of large particle talc for safe pleurodesis. ${ }^{7}$ We have tried to incorporate some important scientific topics to balance the clinical content and described important pathological mechanisms of disease ${ }^{8}$ and emerging genetic mechanisms. ${ }^{9}$

It has been a privilege to edit Lung Alerts as this job has allowed us to keep up to date with the literature and put us in contact with many readers of Thorax everywhere. We hope others find Lung Alerts as interesting as we do. We would like to take the opportunity to thank Angshu's previous Lung Alert co-editors-Terence Seemungal and John Hurst.
Competing interests None.

Provenance and peer review Commissioned; not externally peer reviewed.

Thorax 2010;65:767-768.

doi:10.1136/thx.2010.146100

\section{REFERENCES}

1. Quint J. Allergic sensitisation to peanut may occur through inflamed skin. Thorax 2003;58:469

2. Bhatia $\mathbf{P}$. Radiofrequency ablation of lung cancer. Thorax 2003;58:771.

3. Roy-Choudhury S. Inflammation caused by radiofrequency ablation for lung cancer is worse after radiotherapy and in large tumours. Thorax 2008;63:998.

4. Banerjee AK. Oral gefitinib produces symptomatic and radiological benefit in advanced NSCLC. Thorax 2004;59:104.

5. Powrie DJ. The BODE index: a new grading system in COPD. Thorax 2004;59:427.

6. Navani N. Preoperative integrated PET-CT scanning reduces the number of futile thoracotomies for lung cancer. Thorax 2009;64:1089.

7. Najib M. Pleurodesis with large-particle talc poudrage is safe in malignant pleural effusion. Thorax 2007;62:897.

8. Fletcher CE. IL6 and dendritic cells in allergic asthma. Thorax 2008;63:731.

9. Curley R. Mutations in the LKBI tumour suppressor gene linked to non-small cell lung cancer in Caucasians. Thorax 2009;64:267. 